\title{
The Effects of the Nursing Practice Environment and Self-leadership on Person-centered Care Provided by Oncology Nurses
}

\author{
Sun-Ui Shin, R.N., M.S.N. and Hyun-E Yeom, R.N., Ph.D. \\ Chungnam National University College of Nursing, Daejeon, Korea
}

Purpose: This study aimed to investigate the effects of the nursing practice environment and self-leadership on person-centered care provided by oncology nurses. Methods: This cross-sectional study included 145 nurses who worked in oncology wards at eight university hospitals in Seoul, Daejeon, and Chungcheong Province with at least six months of experience. Data were collected using a self-administered survey and analyzed using descriptive statistics, Pearson correlation coefficients, the $t-$ test, analysis of variance, and hierarchical multiple regression analysis in SPSS version 26.0. Results: Person-centered care was significantly correlated with the nursing practice environment $(r=0.27, \mathrm{P}<0.001)$ and self-leadership $(r=0.40, P<0.001)$, and the nursing practice environment was correlated with self-leadership $(r=0.380, P<0.001)$. Hierarchical multiple regression analysis showed that the nursing practice environment was a significant predictor of person-centered care ( $\beta=0.31, P<0.001$ ), after adjusting for covariates including monthly salary, total clinical career, and the position of oncology nurses. Self-leadership was a significant predictor of person-centered care $(\beta=0.34, \mathrm{P}<0.001)$ after controlling for the nursing practice environment, along with covariates. The final model explained $18.7 \%$ of the variance in personcentered care. Conclusion: Our findings emphasize the importance of the nursing practice environment and nurses' self-leadership for providing person-centered care in oncology care units. Educational programs to reinforce nurses' self-leadership and administrative support for nursing practice are necessary to improve oncology nurses' capability to provide person-centered care.

Key Words: Work, Environment, Leadership, Nurses, Oncology nursing, Patient-centered care
Received July 7, 2021

Revised July 31, 2021

Accepted August 2, 2021

\section{Correspondence to}

Hyun-E Yeom

ORCID:

https://orcid.org/0000-0001-6541-7526

E-mail:yeom@cnu.ac.kr

This article is a revision of the first author's master's thesis from Chungnam National University.

\section{INTRODUCTION}

\section{Background}

With developments in medical science and improved living standards, the paradigm of medical care is shifting from a supply-centered approach to an approach focusing on tailored, consumer-centered services [1]. Along with this transition, patient-centered care has been considered an essential component of the quality of care. The critical role of healthcare providers in performing person-centered care has also been highlighted, particularly when caring for patients in

This is an Open Access article distributed under the terms of the Creative Commons Attribution Non-Commercial License (http://creativecommons.org/licenses/by-nc/4.0/) which permits unrestricted non-commercial use, distribution, and reproduction in any medium, provided the original work is properly cited.

Copyright @ 2021 by Korean Society for Hospice and Palliative Care 
severe conditions with various care needs [2]. In addition, a large body of literature has shown positive effects of personcentered care, in terms of patients' satisfaction and quality of life, the duration of hospitalization, the frequency of medical accidents, and medical costs, on both patients and the medical environment. Therefore, person-centered care is emphasized as an essential element to enhance the quality of medical services [3,4].

Person-centered care is defined as care focusing on individual demands of patients regarding their therapeutic choices and decisions to ensure dignity and autonomy as human beings [3]. Cancer patients often experience a wide range of pain and face diverse challenges that may trigger psychological distress, such as fear about the therapeutic process and uncertainty, highlighting the importance of person-centered care for cancer patients [5]. Furthermore, the therapeutic approaches and clinical prognosis of cancer patients can be diverse, according to the socio-demographic characteristics and the clinical features of cancer. Therefore, it is essential to provide personcentered care based on the individualized care needs of cancer patients [6].

Previous studies have reported that person-centered care is intimately associated with the work environment of nursing practice [7] and intrapersonal factors of nurses, such as selfconfidence and a sense of responsibility [8-10]. The nursing practice environment refers to facilities' human resources and physical capital linked to conducting nursing implementation. The nursing practice environment encompasses the clinical work system, interpersonal relationships between colleagues, an opportunity to participate in the decision-making process, and the leadership skills of unit managers [11]. Many studies have shown that a nursing practice environment encompassing teamwork based on supportive interactions and a suitable administrative system are critical issues related to patient safety and the quality of care regarding the incidence of medical complications and errors, as well as the mortality rate [1216]. Therefore, the nursing practice environment needs to be integrated as a vital element of person-centered care [12-16]. The clinical work environment of oncology nurses is unique because nursing practices include specific nursing skills and knowledge, such as administering chemotherapy and antineoplastic medicines and managing medical devices [17,18]. In addition, oncology nurses need the competencies to respond to patients' complex needs and unpredictable conditions due to the high clinical severity of cancer patients [17]. Further, empirical studies, including systematic reviews, have provided strong evidence supporting the impacts of several components representing the nursing practice environment (e.g., systemic support, opportunities for participation in the decision-making process, and interpersonal relationships) on nurses' jobrelated satisfaction and exhaustion, as well as the quality of care across various care units [16,17]. These findings highlight a critical need to consider the nursing practice environment of oncology units to improve the quality of care and personcentered care for cancer patients.

Self-leadership is another essential component that needs to be considered as an inherent characteristic of nurses for person-centered care. Self-leadership is defined as leadership that empowers a person with autonomy and motivation and drives subjective action, constituting an element that sparks internal inspiration for action and engenders commitment and dedication $[8,18]$. Previous studies [8-10] have established that selfleadership plays a crucial role in enhancing the efficiency of nursing practices and the quality of care by supporting the development of competence in professional nursing care. Therefore, the self-leadership of nurses may become a vital factor related to person-centered care. In particular, cancer patients have multifaceted care demands due to physical and psychosocial distress, indicating the significance of oncology nurses' person-centered care.

Furthermore, self-leadership is a crucial attribute that oncology nurses provide care for cancer patients with autonomous motivation and confidence by utilizing medical knowledge and abilities to practice [8]. However, although several studies have found that self-leadership affects person-centered care among Korean nurses working at different internal medicine and surgical units [10], little is known about the impact of oncology nurses' self-leadership on person-centered care. In addition, studies have rarely considered the influence of the nursing practice environment and self-leadership regarding the person-centered care that oncology nurses provide.

Therefore, this study aimed to provide basic information to improve the person-centered care of oncology nurses by identifying the impact of the nursing practice environment and 
their self-leadership.

\section{Purpose}

The purpose of this study was to identify the impact of the nursing practice environment perceived by oncology nurses and their self-leadership on person-centered care. The specific goals were as follows:

- To identify differences in person-centered care according to the socio-demographic characteristics of oncology nurses.

- To identify correlational relationships between the nursing practice environment, self-leadership, and person-centered care.

- To identify the impact of the nursing practice environment and self-leadership on person-centered care provided by oncology nurses.

\section{METHODS}

\section{Study design}

This cross-sectional descriptive study investigated the impacts of the nursing practice environment and self-leadership on person-centered care provided by oncology nurses.

\section{Participants}

Convenience sampling was used to recruit nurses who worked in oncology wards at eight university hospitals in Seoul, Daejeon, and Chungcheong Province. Inclusion criteria for participation in this study were nurses who provided direct care interventions for cancer patients, had a minimum of 6 months of experience in oncology wards, understood the purpose of this study, and voluntarily signed a written informed consent form.

The number of participants required for this study was calculated using $G^{*}$ Power version 3.1.9.4. With the conditions of a medium effect size (0.15) for multiple regression analysis, 13 predictors at a 0.05 significance level, and statistical power of 0.80 based on a previous study about person-centered care [19], a minimum of 131 participants was required. Considering the fact that self-administered surveys are often accompanied by missing data, the number of target samples was determined as 145 by adding a $10 \%$ incompletion rate.

\section{Study tools}

\section{1) Person-centered care}

Person-centered care was assessed using the Person-centered Critical Care Nursing (PCCN) instrument [20]. The PCCN consists of 15 items classified into four domains: compassion, individuality, respect, and comfort. The original PCCN scale was developed targeting ICU nurses. Fourteen items were applicable for this study, but one item (i.e., "Have you made efforts to minimize unpleasant odors in the ICU?"), explicitly focusing on the ICU environment, was modified for oncology nurses by revising the term "ICU" to "unit". All items assess the degree of agreement with a 5-point Likert scale: 1 for "strongly disagree", 2 for "disagree", 3 for "neutral", 4 for "agree", and 5 for "strongly agree". An average score for all items is calculated, with a higher score denoting more excellent personcentered nursing. The internal consistency of the PCCN was shown by a Cronbach's $\alpha$ value of 0.84 in a previous study [20] and 0.84 in this study.

\section{2) Nursing practice environment}

The nursing practice environment was assessed using the Korean Nursing Work Environment Scale [21]. This scale consists of four domains, including 30 items: institutional support with 12 items, head nurses' leadership with seven items, work system with six items, and relationships with coworkers with five items. Each item is assessed on a 5-point Likert scale, with scores of 1 for "strongly disagree", 2 for "disagree", 3 for "neutral", 4 for "agree", and 5 for "strongly agree". The mean score is calculated for all items, and a higher score indicates more positive perceptions of the nursing practice environment. The internal consistency in this study was the same as the original study that initially reported the reliability, with Cronbach's $\alpha=0.92$ [21].

\section{3) Self-leadership}

Self-leadership was measured using a modified Korean version of the self-leadership scale [22], whose original was developed by Manz and Sims [18]. The scale consists of six domains: three items for self-expectation, three items for rehearsal, three items for creating goals, three items for self- 
compensation, three items for self-criticism, and three items for constructive thoughts. Respondents rate the frequency of each item on a 5-point Likert scale: 1 for "never", 2 for "rarely", 3 for "sometimes", 4 for "often", and 5 for "always". The mean score is calculated for all items, and higher scores reflect a higher level of self-leadership. As a measure of internal consistency, Cronbach's $\alpha$ was 0.92 in the previous study by Kim [22] and 0.80 in this study.

\section{4) General characteristics}

The general characteristics of the participants were assessed regarding gender, age, marital status, religion, average monthly salary, and level of education. In addition, work-related factors were evaluated regarding the duration of work in the oncology ward, job position, and leadership education experience.

\section{Data collection and ethical considerations}

The institutional review board of the researchers' affiliated institution approved the purposes and procedures of this study (202001-SB-010-01). The researchers contacted the executive director for the nursing division of university hospitals in Seoul, Daejeon, and Chungcheong Province via landline and $\mathrm{e}^{-}$-mail to explain the purposes and processes of the study and finally received approval from eight hospitals.

To collect data, the primary investigator visited each hospital and provided information about the purpose and step-bystep process of this study, as well as the policies to protect the rights of the participants. The flyer to recruit participants was posted to a public board in units.

Data were collected by self-administered surveys. Nurses interested in this study opened a single packet containing an $\mathrm{ex}^{-}$ planatory note, a written consent form, and a structured questionnaire. After reading the explanatory memorandum, a nurse who would like to participate in the study voluntarily filled out the written consent form and responded to the questionnaire. The explanatory note provided information about the purpose and procedure of the study, potential benefits and risks of the study, and the participants' rights, such as the freedom to withdraw from participation.

The questionnaires that participants completed were kept sealed, and the primary investigator collected them. In addi- tion, participants were offered small gifts as rewards. The data were collected from April 5, 2020, to May 31, 2020, and the data will be saved and used only for research purposes for the next three years.

\section{Data analysis}

The data were analyzed using SPSS for Windows version 26.0 (IBM Corp., Armonk, NY, USA).

- Descriptive statistics for the participants' general characteristics and main study variables were performed using frequency, percentage, standard deviation, and maximum and minimum values.

- The $\mathrm{t}^{-}$test and analysis of variance were conducted to test differences in person-centered care according to the participants' general characteristics.

- The correlations between the nursing practice environment, self-leadership, and person-centered care were analyzed using Pearson correlation coefficients.

- Hierarchical multiple regression analysis was performed to evaluate the impact of the nursing practice environment and self-leadership on person-centered care.

\section{RESULTS}

\section{General characteristics of participants}

All participants were women, and most participants were under 30 years of age $(n=100,69.0 \%)$ and were not married $(n=124,85.5 \%)$. In addition, a majority of the participants $(n=122,84.2 \%)$ had a bachelor's degree, and 101 (69.7\%) participants did not have a religious affiliation (Table 1).

Participants had an average of $61.67 \pm 55.18$ months of total clinical experience; 86 (59.3\%) of the participants had less than 60 months of clinical experience, 41 (28.3\%) had between 60 and 120 months, and 18 (12.4\%) had more than 120 months of experience. The majority of the participants worked as staff nurses $(134 ; 92.4 \%)$, while $11(7.6 \%)$ were charge nurses. Ninety-two (63.4\%) nurses' monthly income was below 3 million KRW, while 53 (36.6\%) had a monthly salary of more than 3 million KRW. Ninety-seven (66.9\%) nurses stated that they had never received leadership education. 
Table 1. General Characteristics of the Participants ( $N=145)$.

\begin{tabular}{|c|c|c|c|}
\hline Characteristics & Categories & $\mathrm{n}(\%)$ & $\mathrm{M} \pm \mathrm{SD}$ \\
\hline Gender & Female & $145(100.0)$ & \\
\hline \multirow[t]{2}{*}{ Age (yr) } & $<30$ & $100(69.0)$ & \\
\hline & $\geq 30$ & $45(31.0)$ & \\
\hline \multirow[t]{2}{*}{ Marital status } & Single & $124(85.5)$ & \\
\hline & Married & $21(14.5)$ & \\
\hline \multirow[t]{2}{*}{ Religion } & Yes & 44 (30.3) & \\
\hline & No & $101(69.7)$ & \\
\hline \multirow[t]{3}{*}{ Educational level } & Associate's degree & $17(11.7)$ & \\
\hline & Bachelor's & $122(84.2)$ & \\
\hline & Master's or beyond & $6(4.1)$ & \\
\hline \multirow[t]{3}{*}{ Clinical experience (mo) } & $\leq 60$ & $86(59.3)$ & $61.67 \pm 55.18$ \\
\hline & $61 \sim 119$ & $41(28.3)$ & \\
\hline & $\geq 120$ & $18(12.4)$ & \\
\hline \multirow[t]{2}{*}{ Job position } & Staff nurse & $134(92.4)$ & \\
\hline & Charge nurse & $11(7.6)$ & \\
\hline \multirow[t]{2}{*}{ Average monthly salary (10,000 won) } & $<300$ & $92(63.4)$ & \\
\hline & $\geq 300$ & $53(36.6)$ & \\
\hline \multirow[t]{2}{*}{ Experience of leadership education } & Yes & $48(33.1)$ & \\
\hline & No & $97(66.9)$ & \\
\hline
\end{tabular}

\section{Levels of nursing practice environment, self-leadership, and person-centered care}

Information on the overall and sub-domain characteristics of the nursing practice environment, self-leadership, and personcentered care of oncology nurses is shown in Table 2.

The mean nursing practice environment score was $3.28 \pm 0.51$. The highest score for its sub-components was found for the work system (3.82 \pm 0.59$)$, followed by head nurses' leadership (3.81 \pm 0.79$)$, relationships with coworkers $(3.48 \pm 0.67)$, and institutional support $(2.61 \pm 0.68)$.

Self-leadership had a mean score of $3.28 \pm 0.38$, with the highest score for self-compensation $(3.56 \pm 0.61)$, followed by rehearsal (3.47 \pm 0.62$)$, self-criticism $(3.35 \pm 0.84)$, selfexpectation ( $3.19 \pm 0.57)$, constructive thoughts (3.11 \pm 0.56$)$, and creating goals $(3.00 \pm 0.71)$.

Person-centered care had a mean score of $3.74 \pm 0.42$. The highest score was found for respect (3.90 \pm 0.55$)$, followed by comfort (3.73 \pm 0.52$)$, individuality (3.73 \pm 0.49$)$, and compassion $(3.59 \pm 0.60)$.

\section{Differences in person-centered care according to participants' general characteristics}

Person-centered care was significantly different according
Table 2. Scores for the Nursing Practice Environment, Self-leadership, and Person-centered Care.

\begin{tabular}{lc}
\hline \multicolumn{1}{c}{ Characteristics } & $\mathrm{M} \pm \mathrm{SD}$ \\
\hline Nursing practice environment & $3.28 \pm 0.51$ \\
Work system & $3.82 \pm 0.59$ \\
Head nurses' leadership & $3.81 \pm 0.79$ \\
Relationship with coworkers & $3.48 \pm 0.67$ \\
Institutional support & $2.61 \pm 0.68$ \\
Self-leadership & $3.28 \pm 0.38$ \\
Self-compensation & $3.56 \pm 0.61$ \\
Rehearsal & $3.47 \pm 0.62$ \\
Self-criticism & $3.35 \pm 0.84$ \\
Self-expectation & $3.19 \pm 0.57$ \\
Constructive thoughts & $3.11 \pm 0.56$ \\
Creating goals & $3.00 \pm 0.71$ \\
Person-centered care & $3.74 \pm 0.42$ \\
Respect & $3.90 \pm 0.55$ \\
Comfort & $3.73 \pm 0.52$ \\
Individuality & $3.73 \pm 0.49$ \\
Compassion & $3.59 \pm 0.60$ \\
\hline
\end{tabular}

to income level $(t=2.26, P=0.026)$. However, the participants' age, marital status, educational level, clinical experience, and leadership education experience did not display significant associations with person-centered care (Table 3). 
Table 3. Differences in Person-centered Care According to the General Characteristics of Oncology Nurses ( $N=145)$.

\begin{tabular}{|c|c|c|c|c|c|}
\hline \multirow{2}{*}{ Characteristics } & \multirow{2}{*}{ Categories } & \multirow{2}{*}{$\mathrm{n}$} & \multicolumn{3}{|c|}{ Person-centered care } \\
\hline & & & $\mathrm{M} \pm \mathrm{SD}$ & tor $F$ & $P$ \\
\hline \multirow[t]{2}{*}{ Age (yr) } & $<30$ & 100 & $3.72 \pm 0.42$ & 0.82 & 0.415 \\
\hline & $\geq 30$ & 45 & $3.78 \pm 0.40$ & & \\
\hline \multirow[t]{2}{*}{ Marital status } & Single & 124 & $3.73 \pm 0.43$ & -0.92 & 0.358 \\
\hline & Married & 21 & $3.82 \pm 0.32$ & & \\
\hline \multirow[t]{2}{*}{ Religion } & Yes & 44 & $3.80 \pm 0.41$ & 1.03 & 0.305 \\
\hline & No & 101 & $3.72 \pm 0.42$ & & \\
\hline \multirow[t]{3}{*}{ Educational level } & Associate's degree & 17 & $3.76 \pm 0.31$ & 0.27 & 0.768 \\
\hline & Bachelor's & 122 & $3.73 \pm 0.43$ & & \\
\hline & Master's or beyond & 6 & $3.86 \pm 0.25$ & & \\
\hline \multirow[t]{3}{*}{ Clinical experience (mo) } & $\leq 60$ & 86 & $3.72 \pm 0.42$ & 0.83 & 0.438 \\
\hline & $61 \sim 119$ & 41 & $3.73 \pm 0.45$ & & \\
\hline & $\geq 120$ & 18 & $3.86 \pm 0.30$ & & \\
\hline \multirow[t]{2}{*}{ Job position } & Staff nurse & 134 & $3.73 \pm 0.42$ & -1.04 & 0.301 \\
\hline & Charge nurse & 11 & $3.87 \pm 0.36$ & & \\
\hline \multirow[t]{2}{*}{ Average monthly salary $(10,000 \mathrm{KRW})$} & $<300$ & 92 & $3.68 \pm 0.40$ & 2.26 & 0.026 \\
\hline & $\geq 300$ & 53 & $3.84 \pm 0.43$ & & \\
\hline \multirow[t]{2}{*}{ Experience of leadership education } & Yes & 48 & $3.73 \pm 0.36$ & -0.17 & 0.867 \\
\hline & No & 97 & $3.75 \pm 0.44$ & & \\
\hline
\end{tabular}

Table 4. Correlations between Person-centered Care, the Nursing Practice Environment and Self-leadership.

\begin{tabular}{lccc}
\hline \multirow{2}{*}{ Variables } & Person-centered care & \multicolumn{2}{c}{ Nursing practice environment } \\
\cline { 2 - 3 } & \multicolumn{1}{c}{$r(P)$} & - \\
\hline Nursing practice environment & $0.27(0.007)$ & $0.38(<0.001)$ \\
Self-leadership & $0.40(<0.001)$ & \\
\hline
\end{tabular}

\section{Correlations between the nursing practice environment, self-leadership, and person-centered care}

Person-centered care was positively correlated with the nursing practice environment $(r=0.27, \mathrm{P}=0.007)$ and selfleadership ( $\mathrm{r}=0.40, \mathrm{P}<0.001)$. The nursing practice environment and self-leadership also had a positive correlation with each other $(r=0.38, \mathrm{P}<0.001)$ (Table 4).

\section{Factors affecting person-centered care}

Hierarchical regression analysis was performed step-by-step in three models that included the general characteristics of oncology nurses in the first model, the nursing practice environment in the second model, and the self-leadership in the third model as factors affecting person-centered care. The results are shown in Table 5. The Durbin-Watson statistic had a value of 1.874 , close to 2 , indicating no autocorrelation between the sum of errors in the models. At the same time, multicollinearity did not occur at a problematic level, as the tolerance was above 0.1 and all variance inflation factor values were below 10.

The first model in the hierarchical regression analysis showed that none of the general characteristics of oncology nurses (e.g., average monthly salary, clinical experience, and job position) were predictors of person-centered care, unlike the findings of a previous study [23].

The second model included the nursing practice environment in addition to the first model. After adjusting for the effects of the nurses' general characteristics, the nursing practice environment was found to significantly influence person-centered care $(\beta=0.31, P<0.001)$, with an $8 \%$ higher explanatory power than that of the first model.

The third model added self-leadership to the second model. 


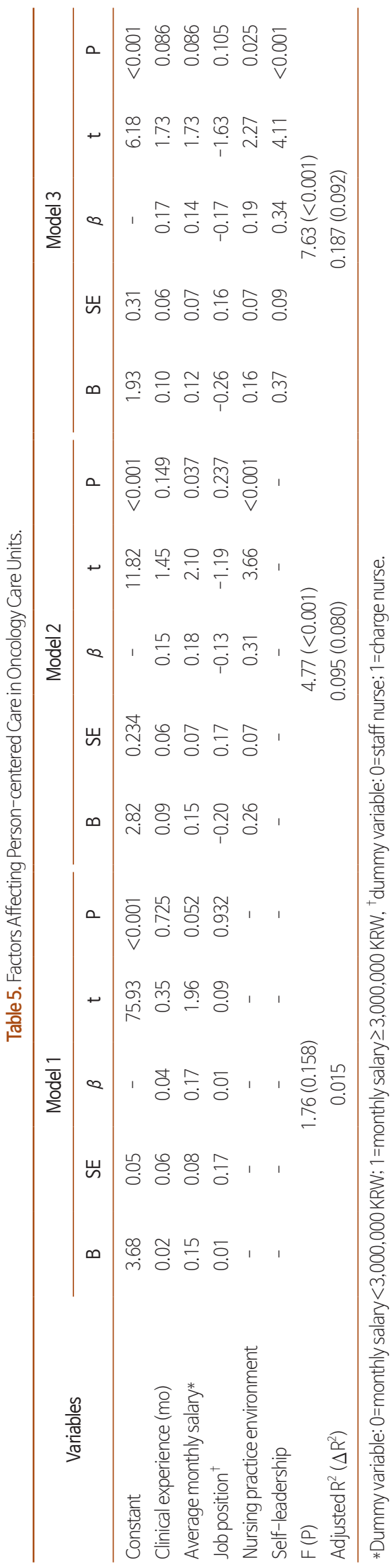

After controlling for the effects of average monthly salary, clinical experience, job position, and nursing practice environment, self-leadership was a significant predictor of personcentered care $(\beta=0.34, \mathrm{P}<0.001)$. The average monthly salary level that showed a substantial effect in the second model was no longer statistically significant ( $\beta=0.14, \mathrm{P}=0.086$ ). In contrast, the nursing practice environment influenced person-centered care considerably $(\beta=0.19, \mathrm{P}<0.05)$. The explanatory power of the final model increased by $9.2 \%$ compared to that in the second model, and it was statistically significant $(\mathrm{F}=7.63$, $\mathrm{P}<0.001)$. The overall explanatory power for person-centered care was $18.7 \%$.

\section{DISCUSSION}

This study was conducted to identify the effects of the nursing practice environment and self-leadership as factors influencing person-centered care provided by oncology nurses.

The average score for person-centered care among oncology nurses was $3.74 \pm 0.42$, which is somewhat higher than those (i.e., 3.52 3.70) reported in previous studies about ICU nurses $[23,24]$. This study found a direct correlation between personcentered care and average monthly salary, consistent with earlier studies about nurses in rehabilitation facilities [3]. In addition, some previous studies [23] found that nurses' age and clinical experience were associated with person-centered care. However, such associations were not detected in this study. There is limited information about the person-centered care provided by oncology nurses and the related factors. Therefore, further studies including more participants from various institutions are warranted to clarify the socio-demographic characteristics of nurses related to person-centered care.

With regard to the nursing practice environment perceived by oncology nurses, the average score in the current study was $3.28 \pm 0.51$. This score is relatively higher than the score ( 2.98 \pm 0.39 ) shown in previous studies about ICU nurses [23]. The average score of self-leadership among oncology nurses was $3.28 \pm 0.38$, which is the middle level of the scores (3.21 3.51) shown among general hospital nurses $[9,25]$. There were significant correlational relationships between the nursing practice environment, self-leadership, and person-centered care. Nurses with more positive perceptions of the work environ- 
ment tended to have greater self-leadership $(r=0.38, \mathrm{P}<0.001)$. In addition, nurses who reported higher levels of personcentered care tended to perceive more positive perceptions about the nursing practice environment $(\mathrm{r}=0.27, \mathrm{P}=0.007)$ and greater self-leadership $(r=0.40, P<0.001)$. These findings are consistent with previous evidence that the work environment or nursing practice (e.g., organizational structure and teamwork for nursing practice) are related to autonomous activities and compassion of nurses, which are essential components for person-centered care $[10,13,19]$.

The current study confirmed the critical impacts of the nursing practice environment and nurses' self-leadership on the person-centered care provided by oncology nurses after taking into account the influence of their general socio-demographic characteristics. That is, the work-related environmental factors (i.e., nursing practice environment) and nurses' intrapersonal factors reflecting autonomous nursing practice (i.e., selfleadership) need to be considered essential issues for personcentered care.

These findings emphasize the critical significance of a supportive environment for nursing practice and self-leadership to improve person-centered care, as highlighted by previous results from various nursing units (e.g., in internal medicine or surgical units of tertiary hospitals, the ICU, or the emergency room) $[10,19,23,26]$. Furthermore, this study indicates that the nursing practice environment and self-leadership are essential determinants of person-centered care in oncology nurses, who have multiple responsibilities in caring for cancer patients. Therefore, the findings highlight the critical need to improve the efficiency in organizational and practical systems for nursing practices and teamwork based on supportive interactions between colleagues. In addition, the effort to enhance nurses' self-leadership is necessary regarding the intimate connection to the nursing practice environment.

In addition, this study investigated the relative contributions of nursing practice environment and self-leadership on person-centered care using the step-by-step approach. After controlling for the influence of nurses' general socio-demographic characteristics, there was an increase of $8 \%$ in explaining the variance of person-centered care. Moreover, the explanatory power additionally increased by $9.2 \%$ when the influence of self-leadership was counted, amounting to a total of $18.7 \%$. These findings indicate that self-leadership had a more significant impact on person-centered care provided by oncology nurses than the influence of the nursing practice environment. This implies that reinforcing the self-leadership of oncology nurses needs to be emphasized as a more vital issue for active practice incorporating person-centered care, even though constructing an effective work environment is also essential for person-centered care. However, the interpretation regarding the relative effects is not definitive because limited research has examined the influence of both the nursing practice environment and self-leadership of nurses on personcentered care. Therefore, further studies that include both issues are warranted to draw a clear picture of the impacts of environmental and intrapersonal factors on the personcentered care provided by oncology nurses.

A few limitations should be noted. First, the data for this study were collected by a convenience sampling of oncology nurses at general hospitals. Therefore, it is necessary to be cautious not to generalize the findings, which represent the characteristics of oncology nurses as a whole. Despite this limitation, this study is still meaningful as it provides primary evidence to develop a strategy for person-centered care for oncology patients. Another limitation is that the information of the person-centered care was collected by self-administered surveys, which may not represent the actual practice of person-centered care. Since person-centered care is a nursing activity based on interactions between nurses and patients, the objective characteristics of person-centered care need to be investigated through a comparative evaluation of nurses and patients. Lastly, the interpretation of this study requires caution as it employed a tool developed for ICU nurses to measure person-centered care. However, critical elements of personcentered care are applicable across various nursing units; it is necessary to develop and apply a tool that focuses on personcentered care of oncology nurses, given the clinical distinctiveness of cancer patients.

With the persistent increase in cancer incidence rates and the variety of therapeutic approaches, the importance of personcentered care in oncology units has been highlighted. This study confirmed that aspects of the nursing practice environment in the oncology unit and nurses' self-leadership were critical factors associated with person-centered care. As such, 
it is necessary to create an organized and systematic work environment to support the efficient practice of oncology nurses and make improvements at the administrative level. In addition, educational programs should also be developed and implemented to reinforce the self-leadership of oncology nurses since self-leadership encourages their sense of responsibility and drives autonomous nursing practice. Furthermore, continuing research is needed to identify changes in personcentered care by implementing educational initiatives and policies to improve the nursing practice environment in oncology wards and reinforce self-leadership.

\section{CONFLICT OF INTEREST}

No potential conflict of interest relevant to this article was reported.

\section{ORCID}

Sun-Ui Shin, https://orcid.org/0000-0003-3373-0803

Hyun-E Yeom, https://orcid.org/0000-0001-6541-7526

\section{AUTHOR'S CONTRIBUTIONS}

Conception or design of the work: SUS, HEY. Data collection: SUS. Data analysis and interpretation: SUS, HEY. Drafting the article: SUS. Critical revision of the article: HEY. Final approval of the version to be published: SUS, HEY.

\section{SUPPLEMENTARY MATERIALS}

Supplementary materials can be found via https://doi. org/10.14475/jhpc.2021.24.3.174.

\section{REFERENCES}

1. Kang HJ. The 21st OECD Health Committee: Towards people centered health care system. Global Social Security Review 2017;2:118-23.

2. Lusk JM, Fater K. A concept analysis of patient-centered care. Nursing Forum 2013;48:89-98.

3. Sagong H, Lee GE. Person-centered care and nursing service quality of nurses in long-term care hospitals. J Korean Acad Community Health Nurs 2016;27:309-18.

4. Charmel PA, Frampton SB. Building the business case for patient-centered care. Healthc Financ Manage 2008;62:80-5.

5. Wu CS, El Rayes BF. A patient centered team approach in oncology. Cancer 2018;124:1856-8.

6. Kang JY, Suh EE. Perceptions of quality of patient-centered nursing care among women with breast cancer. Perspectives in Nursing Science 2015;12:115-23.

7. McCormack B, McCance TV. Development of a framework for person-centered nursing. J Adv Nurs 2006;56:472-9.

8. Won HJ, Cho SH. A review of research on self-leadership in nurses. J Korean Nurs Adm Acad Soc 2013;19:382-93.

9. Seomun GA, Jang SO, Cho KH, Kim IA, Lee SJ. The relation between self-leadership and outcome of nursing practice. J Korean Nurs Adm Acad Soc 2006;12:151-8.

10. Jeong H, Park MH. A predictive model on patient-centered care of hospital nurses in Korea. J Korean Acad Nurs 2019;49:191-202.

11. Lake ET. Development of the practice environment scale of the Nursing Work Index. Res Nurs Health 2002;25:176-88.

12. Kim SB, Park YR. Factors associated with person-centered care for elderly in long-term care hospital nurses. Korean J Adult Nurs 2019;31:618-27.

13. Aiken LH, Clarke SP, Sloane DM, Lake ET, Cheney T. Effects of hospital care environment on patient mortality and nurse outcomes. J Nurs Adm 2008;38:223-9.

14. Lin L, Liang BA. Addressing the nursing work environment to promote patient safety. Nursing forum 2007:42:20-30.

15. Han MY, Lee MS, Bae JY, Kim YS. Effects of nursing practice environment, compassion fatigue and compassion satisfaction on burnout in clinical nurses. J Korean Nurs Adm Acad Soc 2015;21:193-202.

16. Papastavrou E, Acaroglu R, Sendir M, Berg A, Efstathiou G, Idvall E, et al. The relationship between individualized care and the practice environment: an international study. Int J Nurs Stud 2015;52:121-33.

17. Friese CR. Nurse practice environments and outcomes: implications for oncology nursing. Oncol Nurs Forum 2005;32:765-72.

18. Manz CC, Sims HP Jr. SuperLeadership: Beyond the myth of heroic leadership. Organ Dyn 1991;19:18-35.

19. Park EM, Park JH. Influence of moral sensitivity and nursing practice environment in person-centered care in long-term care hospital nurses. J Korean Gerontol Nurs 2018;20:109-18.

20. Kang J, Cho YS, Jeong YJ, Kim SK, Yun SY, Shim MY. Development and validation of a measurement to assess person-centered critical care nursing. J Korean Acad Nurs 2018;48:323-34. 
21. Park SH, Kang J. Development and psychometric evaluation of the Korean nursing work environment scale. J Korean Crit Care Nurs 2015;8:50-61.

22. Kim HS. The relationship between teachers' self-leadership and the job satisfaction at secondary schools [master's thesis]. Seoul: Soongsil Univ.; 2003. Korean.

23. Kang J, Lim YM. The relationship between the work environment and person-centered critical care nursing for intensive care nurses. J Korean Crit Care Nurs 2019;12:73-84.

24. Kang J, Shin EJ. The relationship between person-centered nursing and family satisfaction in ICUs. J Korean Crit Care Nurs 2019;12:1-12.

25. Baek JS. Effects of workplace spirituality and self-leadership on nursing performance of clinical nurses [master's thesis]. Busan: Kosin Univ.; 2019.

26. Lee YM. Nursing practice environment, job stress and person-centered care in geriatric hospital nurses. JKDAS 2018;20:2635-47. 